\title{
EXPLORING KNOWLEDGE MANAGEMENT PERCEPTIONS AMONG INFORMATION SYSTEMS MANAGERS - EMPIRICAL SENSE-MAKING THROUGH FOCUS GROUP RESEARCH
}

\author{
David Yuh Foong LAW \\ Department of Decision Sciences \\ Business School, National University of Singapore \\ c/o: CMIT, FBA 2, Basement, \\ Business Link, Singapore 117591 \\ fbalawyf@nus.edu.sg ; davidlaw@bigfoot.com \\ Joo Eng LEE-PARTRIDGE \\ Department of Decision Sciences \\ Business School, National University of Singapore \\ FBA I, 15 Law Link, Singapore 117591 \\ fbaleeje@nus.edu.sg ; jooeng@bigfoot.com
}

Keywords: knowledge management, empirical sense-making, frames of reference, focus groups research, information systems management.

\begin{abstract}
Despite the increasing knowledge management (KM) awareness and interest among academia and industry, a very diverse range of views and perceptions still exists. There is a need to appreciate the issues and concerns surrounding KM research and implementation among communities of researchers and practitioners. Our research aims to provide a deeper empirical insight of practitioners in terms of the general level of awareness, the state of practice, and industrial perceptions on KM issues in the context of a growing knowledge-based economy such as Singapore. We chose to explore this topic from an information systems (IS) management perspective, by exploring the levels of KM understanding, the issues of concerns and requirements by chief information officers (CIOs) and senior IS managers, and how they make sense of $\mathrm{KM}$. Sense-making approach through focus group research is the primary methodology used. Using social cognitive research techniques such as frames of reference, the participants' perceptions are summarised and presented broadly along the following themes: conceptual awareness of knowledge/ $\mathrm{KM}$; facilitators and inhibitors of $\mathrm{KM}$; usefulness and value of $\mathrm{KM} ; \mathrm{KM}$ mechanisms and implementation approaches; factors influencing knowledge sharing, acquisition and capture; effectiveness of KM technologies; and the prerequisites of a KM practitioner. Our findings are discussed in the light of their implications to IS management practice in organisations. The findings also raises new research questions in IS and $\mathrm{KM}$.
\end{abstract}

\section{INTRODUCTION}

\section{Overview, Motivation and Objectives}

In the context of Singapore, a small nation whose main resource is human skills and knowledge, it needs to transform into a knowledge-based economy in order to survive and compete economically. The ability and need to effectively exploit the intellectual resources within and around a business domain have thus become a major challenge for knowledge-intensive organisations. Knowledge management $(\mathrm{KM})$ technologies and practices will play a major role in supporting knowledge work and related processes.

$\mathrm{KM}$ is an emerging area of focus where researchers and practitioners of varied background and disciplines approach it from diverse angles and perspectives. From the KM literature, there is no lack of explicit guidelines and approaches developed for KM implementation. Liebowitz ed. (1999) compiled a comprehensive overview of these generic concepts and practical guidelines. $\mathrm{KM}$, given its multidisciplinary and cross-functional nature, as well as its ambiguous definitions and boundaries, its theoretical foundation has not been stabilised, and it has manifested its own cloud of confusion. As KM is an emerging and evolving field, it remains a new an elusive concept to many organisations. Practitioners have encountered difficulties and uncertainties in the adoption and implementation of KM despite their attempts to follow some of the prescribed approaches and guidelines religiously. Some of these difficulties are attributed to specific social, organisational and contextual factors, while others could be due to the misconceptualisation of the actual KM problem which results in the deployment of an inappropriate KM solution. Therefore, despite the increasing volume of publications generated on the subject, the practical know-how commonly recommended by consulting firms and the increasing KM awareness and interest in Singapore, a certain degree of ambiguity still exists. It is still generally unclear how an organisation initiates and implements $\mathrm{KM}$ projects and exactly 
how KM can be applied or contribute to business growth and developments. The current lack of both a well-defined view of the subject and empirical insights have motivated this study of $\mathrm{KM}$-related issues in Singapore.

The primary objective of our research is to carry out a preliminary qualitative assessment of the general level of awareness, the state of practice, and industrial perceptions on KM issues in Singapore. At this juncture, our research does not aim to discover new KM theories or models and attempting to insert them into theory in literature. Instead our contribution focuses on the construction of social cognitive profiles of practitioners as part of our attempt to understand related industry sentiments and practical issues, even as the practitioners are struggling to make sense of $\mathrm{KM}$ concepts themselves. We have chosen to explore this topic from an information systems (IS) perspective. As IS is a key factor behind organisational management and business innovation in Singapore, IS management plays a crucial role in supporting and augmenting business managerial decision-making through the establishment of efficient IS infrastructures. In the context of KM adoption and implementation in organisations, IS managers today face a new set of challenges. These include the need to understand the organisations' business and users' KM needs; aligning the organisations' IS plans to meet these needs; keeping abreast of new and emerging technologies and identifying suitable technologies for $\mathrm{KM}$; and the subsequent task to champion these technologies for their eventual adoption and acceptance in organisations. We surmise that IS managers will play a very important role in supporting new KM initiatives and overseeing IS-based KM implementations. Such considerations have motivated our decision to commence our research on $\mathrm{KM}$ issues and perceptions with IS professionals.

The study was carried out with a number of chief information officers (CIOs) and senior IS executives from various institutions and organisations based in Singapore. Focus group research was used as an effective method for collecting rich and broad-based qualitative data, and the approach is flexible and appropriate for the study of emerging trends and issues. Such a group setting was also ideal for peer interaction, sharing and exchange of opinions and perceptions. In particular from a sense-making perspective, focus groups are extremely useful mechanisms for exploring fuzzy empirical KM issues and to assess the levels of KM understanding among CIOs and senior IS managers. A series of focus group sessions were conducted and the results were extracted and broadly categorised.

This paper presents the collective views and perceptions on KM from an IS practitioner perspective. Using social cognitive structures such as frames of references, the results are broadly framed in categories, such as: awareness and concept of knowledge/KM; facilitators and inhibitors of $\mathrm{KM}$; usefulness and value of $\mathrm{KM} ; \mathrm{KM}$ mechanisms and implementation approaches; factors influencing knowledge sharing, acquisition and capture; effectiveness of KM technologies; and the requirements and qualifications of a $\mathrm{KM}$ practitioner. It includes an analysis and discussion of these empirical results, and their implications for $\mathrm{KM}$, with a view to facilitate the management, development and deployment of IS-based information and decision support systems as strategic KM enablers in organisations.

\section{Knowledge Management}

As the global economy becomes increasingly more knowledge-based in nature, organisations have realised the value of knowledge and the need to manage it effectively. Within organisations, knowledge resources are fast becoming critical intellectual assets with strategic roles in organisational survival and competitiveness. The field of KM is a fast emerging area of interdisciplinary research and practice. $\mathrm{KM}$ is the formalisation of and access to experience, knowledge, and expertise that create new capabilities, enable superior performance, encourage innovation, and enhance customer value (Beckman 1997). The key objectives of KM can be summarised as: firstly to make the enterprise act as intelligently as possible to secure its viability and overall success; and secondly, to otherwise realise the best value of its knowledge assets (Wiig 1997). In essence, KM involves the creation of the environment and opportunities to enhance the potential for co-ordination and synergism between networks and pools of knowledge. Beckman (1997) proposes an eight-stage process for KM: Identify, Capture, Select, Store, Share, Apply, Create and Sell. Alongside these $\mathrm{KM}$ processes which guide and drive the construction of corporate memory repositories, a whole spectrum of advanced information technologies and techniques may be used for supporting the activities in a KM cycle (Wiig et al. 1997). KM can be examined at different levels and explored along a wide range of perspectives. This reveals the diversity and complexity of $\mathrm{KM}$ in research and practice, with converging contributions from various disciplines and perspectives such as organisation and management (HBR 1998), economy and policy-making (OECD 1996), and advanced information technologies (Shariq 1998). The ambiguity and the lack of a commonly accepted definition for KM are perhaps part of the reasons for the confusion surrounding this field, which accounts for the diverse research disciplines it attracts and its slow diffusion to and acceptance by industry. 


\section{RESEARCH CONTEXT AND APPROACH}

KM adoption within organisations in Singapore could be generally described as "a little quiet" despite growing awareness. It seems that a cloud of uncertainty relating to $\mathrm{KM}$ persists among organisations. Organisations in general have not embraced much of KM practices and technologies into their own business and structures, which is in contrast to the enormous effort and attention given to other rapidly developing fields such as e-commerce. With KM technologies and issues emerging rapidly, KM concepts and the level of abstraction increases. As a result, most organisations struggle to comprehend fully the concepts surrounding knowledge, knowledge-intensive work and KM, let alone $\mathrm{KM}$ strategic planning and implementation. The meanings and perceptions of knowledge and $\mathrm{KM}$ also vary between organisations and across industries. In this context, we aim to explore a diverse range of KM-related issues, from the organisational, technological, managerial and conceptual perspectives. In the selection of study subjects or participants, we decided to focus on senior executives and practitioners with IS-related background. The presumption was that this category of participants may tend to perceive a wider picture of $\mathrm{KM}$, especially technology implementation issues, as compared to non-IS participants. Through a series of focus group discussions, we hope to solicit viewpoints, opinions and perceptions from these IS industry leaders and practitioners which could contribute to the empirical-grounding of fresh insights and structures on KM in Singapore. This approach will enable the framing of issues for analysis, highlighting industry concerns, and establishing missing links and new relationships among existing practices and research. We believe this research approach will narrow the gap between academia and practice in a contemporary environment of dynamic business needs and rapid technological development.

\section{RESEARCH METHODOLOGY}

As $\mathrm{KM}$ is still an emerging field in its infancy in Singapore, an exploratory qualitative research strategy is appropriate to solicit opinions and perceptions from various organisations in Singapore. The challenges of environmental uncertainty and problem definition are occasions for sense-making (Weick 1995), which may be situations that are novel, discrepant, or are based on deliberate initiative. With the existence of many ill-defined situations and concepts associated with $\mathrm{KM}$ practice, we decided to adopt the sense-making approach to explore the situation in order to gain clearer insights of industry perceptions. According to Weick (1995), sense-making, in its simplest form, literally means "the making of sense". It is a process which can be understood from various perspectives, such as structuring the unknown or explaining surprises. Focus group research is a useful and effective approach in this context for the study of emerging trends and issues in KM by providing a conducive platform to initiate the process of sensemaking. Focus group is a qualitative research technique in which a group of eight to ten participants of similar demographics, attitudes, or behavioural patterns are led through a (usually) two-hour discussion of a particular topic by a moderator (Greenbaum 1998). This technique has been popularly used in marketing research for gathering consumers reactions towards certain products and services, but has yet to be adopted or accepted in mainstream IS research. In our context, focus groups are very useful mechanisms for making sense of fuzzy empirical KM issues and to assess the levels of KM understanding among CIOs and senior IS managers. For our study of KM issues and perceptions we have adapted the focus group technique as part of an overall grounded theory approach (Strauss and Corbin 1998) to obtain rich and qualitative insights from participants. Large and rich amounts of data in the participants' own words can be readily obtained, thereby enabling them to obtain deeper levels of meaning, make important connections and identify subtle nuances in expression of meaning. Using frames of reference, data from focus groups were first summarised (tables 1-4) and subsequently formalised into explicit structures (figures 1-7) which effectively map the cognitive frameworks of the focus groups participants. This activity represented the first key step in our grounded theory approach, from the perspective of sense-making, where new issues and concepts were induced from raw empirical data. These structures represent a set of cognitive representations where meanings and perceptions are shared, from which research interpretation may be derived or built upon. These frameworks will serve as seed structures as they evolve progressively, grounding on fresh data and insights from focus groups until a point of saturation where the frameworks attain a certain degree of stability.

A series of three separate focus group sessions were conducted with an average of eight participants per group, each in their mid-forties with close to twenty years of industry experience. They were mainly CIOs, IS directors and senior IS executives from eighteen large Singapore-based organisations, across various industries including government bodies, academic institutions, consulting firms and multinational corporations. Each session was audio and video taped for subsequent coding and analysis. It may be useful to note that at this juncture of our research, comparison of our results with general concepts, views, opinions published in the literature is kept to a minimum because one of our objectives here is to solicit true empirical perceptions and issues largely from the participants' own organisational contexts and experiences, as we attempt to make sense of these findings from their unique perspectives. 


\section{PERCEPTIONS AMONG FOCUS GROUP PARTICIPANTS}

The proceedings of all focus group sessions conducted were carefully video and audio-taped for analysis and transcription. The preliminary results documented were extracted and summarised, and broadly tabulated under general categories namely: (1) Perceptions of Knowledge Concepts and KM; (2) Perceptions of the Facilitators and Inhibitors of KM; (3) Perceptions of KM Mechanisms and Tools; and (4) Perceptions of the Roles and Requirements in $\mathrm{KM}$. These findings reveal some of the issues, views and opinions discussed, reflecting the perceptions and concerns of the CIOs and senior IS executives, and a glimpse of the current state of KM adoption in their respective organisations. The issues discussed under each category could be related to any one or a combination of cultural, technological, managerial and other aspects of KM. The data presented here are further analysed in the following section, where they serve as an empirical basis for deeper theoretical reflection, sense-making and new theory induction.

Table 1. Perceptions of Knowledge Concepts and KM.

\begin{tabular}{|l|l|}
\hline KM Issues & Perceptions, Opinions and Views from Focus Group Participants \\
\hline $\begin{array}{l}\text { Knowledge vs } \\
\text { Information }\end{array}$ & $\begin{array}{l}\text { Similarities: knowledge is a summary of information; a subset of information; related or } \\
\text { specific or tailored to a domain, or a task at hand, or to pursue a business objective. } \\
\text { Differences: information is very general, covering wider scope; information can be gathered, } \\
\text { analysed, but may not be internalised, while knowledge can be internalised (tacit), in-built } \\
\text { within individuals. In this sense, knowledge can be regarded as internalised and actionable } \\
\text { information. }\end{array}$ \\
\hline $\begin{array}{l}\text { Examples of } \\
\text { knowledge and } \\
\text { its applications } \\
\text { and the bene- } \\
\text { fits of KM }\end{array}$ & $\begin{array}{l}\text { Knowledge only becomes useful when applied. Knowledge facilitates decision-making by } \\
\text { allowing the person to access best available knowledge in order to make optimal decisions. } \\
\text { Organisational knowledge includes: processes, procedures, best practices (to increase pro- } \\
\text { ductivity), and competitive advantage knowledge (to achieve better customer service, more } \\
\text { profits, larger market share). } \\
\text { KM is the know-how to facilitate the sharing and utilisation of knowledge when it is needed. }\end{array}$ \\
\hline $\begin{array}{l}\text { Experts' knowledge will be increasingly focussed and specialised. } \\
\text { Meta-knowledge ("knowledge about knowledge") helps to track an organisation's intellec- } \\
\text { tual resources and expertise for quick access and retrieval. }\end{array}$ \\
scepticism & $\begin{array}{l}\text { KM effort may not be useful or worthy; some knowledge may not be worth capturing due } \\
\text { to: the nature of short project life cycles; and the quick obsolescence of knowledge and ex- } \\
\text { pertise (out-dated technologies, markets, products, etc.). }\end{array}$ \\
\hline
\end{tabular}


Table 2. Perceptions of the Facilitators and Inhibitors of KM.

\begin{tabular}{|c|c|}
\hline KM Issues & Perceptions, Opinions and Views from Focus Group Participants \\
\hline $\begin{array}{l}\text { Organisational } \\
\text { Culture }\end{array}$ & $\begin{array}{l}\text { Cultivating the appropriate organisational cultural and changing mindsets are among some } \\
\text { of the most important factors for the successful adoption of KM concepts, practices and } \\
\text { technologies. The CEO is the key figure in making or breaking such a culture. }\end{array}$ \\
\hline 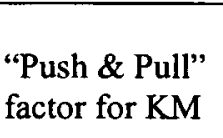 & $\begin{array}{l}\text { The adoption of KM is largely influenced by the interplay between the "push" and "pull" } \\
\text { factors, whereby the CEO should "push" it (KM champion) while the technology providers } \\
\text { will "pull" it (provide KM solutions). }\end{array}$ \\
\hline $\begin{array}{l}\text { Organisational } \\
\text { structure and } \\
\text { existing re- } \\
\text { sources and } \\
\text { infrastructure }\end{array}$ & $\begin{array}{l}\text { An organisation with a relatively flat structure comprising more workgroups and teams are } \\
\text { generally considered more favourable for KM, compared to a more traditional, hierarchical, } \\
\text { multi-layered organisational structure. A KM practitioner should be given the authority to } \\
\text { move around freely within an enterprise, gathering knowledge and accessing knowledge } \\
\text { bases from various departments and sections. Existing organisational structure and } \\
\text { workflow should be modified to reflect such flexibility. } \\
\text { From a technology and resources perspective, the existing infrastructure and management } \\
\text { practices of large organisations in Singapore are quite ready for the adoption and imple- } \\
\text { mentation of new KM initiatives. Generally this does not include intelligent systems. }\end{array}$ \\
\hline $\begin{array}{l}\text { Knowledge } \\
\text { sharing at the } \\
\text { organisational } \\
\text { and individual } \\
\text { levels }\end{array}$ & $\begin{array}{l}\text { Asians tend to be more conserved and reticent, hence cultivating the appropriate knowledge- } \\
\text { sharing mindsets and culture could be relatively more difficult in Asian-based organisations. } \\
\text { Organisational factors that affects knowledge sharing include: identifying sharing motiva- } \\
\text { tors and developing sharing passions; promoting mechanisms and practices to promote } \\
\text { sharing (eg. conferences, seminars, discussion groups), and sharing using innovative tech- } \\
\text { niques (e.g. story-telling); and adopting the appropriate technologies to support sharing pro- } \\
\text { cesses and activities (e.g. groupwares, common knowledge bases, etc). } \\
\text { At the individual level, the factors affecting personal sharing of tacit knowledge could be: } \\
\text { his ability to express his knowledge clearly and adequately; his concerns of losing his expert } \\
\text { status and value in the organisation if he shares; the correctness and completeness of expert } \\
\text { knowledge; and knowledge documentation in an understandable form. } \\
\text { Confidentiality and security issues are also of concern, in developing policies and structures } \\
\text { for organisational knowledge sharing. Suggestions include making selective availability of } \\
\text { knowledge and information to staff with different needs and security access levels, and pos- } \\
\text { sibly on a new-to-know basis. }\end{array}$ \\
\hline $\begin{array}{l}\text { Knowledge } \\
\text { capturing and } \\
\text { documentation }\end{array}$ & $\begin{array}{l}\text { In capturing and documenting knowledge, the symptoms and the prescribed solutions to a } \\
\text { problem are usually recorded, but often the real causes of the problem and the process of } \\
\text { formulating the solution are often not captured. Part of KM should focus on capturing such } \\
\text { previously neglected knowledge. } \\
\text { Also, with the problem of information overload, a person could sometimes be more biased } \\
\text { towards the type of information and knowledge which they wish to extract, with the possi- } \\
\text { bility of missing out on other important aspects. }\end{array}$ \\
\hline $\begin{array}{l}\text { Other pre- } \\
\text { occupations } \\
\text { and external } \\
\text { factors : } \\
\text { 1. Economic } \\
\text { crisis in Asia; } \\
\text { 2. Y2K related } \\
\text { problems } \\
\text { 3. ISO } 9000 \\
\text { and other re- }\end{array}$ & $\begin{array}{l}\text { The economic crisis in Asia over the last couple of years could be a major factor influencing } \\
\text { the decision and rate of KM adoption and diffusion. This may be viewed from two angles: } \\
\text { On one hand, organisations could be more competitive through KM which could enable new } \\
\text { markets entry, offer new products and services. However on the other hand, there is a pres- } \\
\text { sure to cut cost/budget through downsizing business operations, and retrenching high- } \\
\text { salaried employees (unfortunately usually experienced and knowledgeable). It seems that } \\
\text { the latter view has slowed down the adoption of KM practices in organisations. } \\
\text { At the turn of the century, most IT departments have focused their attention and resources } \\
\text { on solving the Y2K millennium problem and developing measures to prevent its occurrence. } \\
\text { Most organisations in Singapore are pursuing ISO } 9000 \text { or related quality management certi- } \\
\text { fication programs, which involves a substantial amount of effort and resources being chan- } \\
\text { nelled to such activities. These programs are generally perceived to have more tangible im- } \\
\text { plementation approaches and measurable outcomes. } \\
\text { The above factors have resulted in organisations freezing or putting on hold KM projects, or }\end{array}$ \\
\hline
\end{tabular}


lated quality management certification

programs shifting these projects to a lower priority. This is especially so, when managers could not associate the outcome/effects of $\mathrm{KM}$ with the direct benefits of applying $\mathrm{KM}$ to their work and business domains.

Table 3. Perceptions of KM Mechanisms and Tools.

\begin{tabular}{|c|c|}
\hline KM Issues & Perceptions, Opinions and Views from Focus Group Participants \\
\hline $\begin{array}{l}\text { Methods and } \\
\text { approaches for } \\
\text { knowledge } \\
\text { capture }\end{array}$ & $\begin{array}{l}\text { In general, tacit knowledge in organisations (eg. a cultural practice, a particular way of do- } \\
\text { ing a project, etc.) are not easily captured as they are not documented or formalised. Some } \\
\text { forms of explicit knowledge could be easily captured through practices such as ISO9000 } \\
\text { procedures/documentation. Other methods of knowledge gathering include interviews and } \\
\text { collecting frequently-asked-questions (FAQs). } \\
\text { Knowledge acquisition should always have clear objectives and reasons. Organisation could } \\
\text { acquire knowledge within itself (eg. operations and processes) and externally (eg. competi- } \\
\text { tors and customers knowledge). Gathered knowledge should be carefully sorted and catego- } \\
\text { rised for effective retrieval and use. } \\
\text { Suggested methods to motivate sharing include: staff suggestion schemes, reward scheme } \\
\text { for sharing and good ideas, conferring recognition, incorporation into staff ap- } \\
\text { praisal/promotion, encourage formation of project teams comprising members from diverse } \\
\text { backgrounds, disciplines, expertise and experiences, etc. }\end{array}$ \\
\hline $\begin{array}{l}\text { Technological } \\
\text { capabilities, } \\
\text { related issues } \\
\text { and general } \\
\text { perceptions }\end{array}$ & $\begin{array}{l}\text { Technological issues are of lower concerns in KM. To support KM adequately, a hybrid of } \\
\text { technologies may be required to support the identification, acquisition, development, dis- } \\
\text { semination, use, and preservation of the enterprise's knowledge. Some of these technologies } \\
\text { are generally available in the market while new ones are actively in the research pipeline. } \\
\text { Popular tools adopted in organisations include groupwares (eg. Lotus Notes), inter- } \\
\text { net/intranet/web servers, search engines, agents, information databases and data warehouses. } \\
\text { Intelligent and knowledge-based technologies (eg. artificial intelligence (Al), expert sys- } \\
\text { tems) are not commonly adopted in organisations, nor regarded as strategic enablers for } \\
\mathrm{KM} \text {. Data mining was only beginning to be adopted by organisations and were only loosely } \\
\text { perceived as a KM tool. Modelling technologies were also not associated with KM in any } \\
\text { way. } \\
\text { Future trends and capabilities of technology should focus on preventing information over- } \\
\text { load; possess effective retrieval mechanisms, and intelligent means of personalising knowl- } \\
\text { edge gathering, selection and delivery. With this wide spectrum of technologies to select } \\
\text { from, the main challenge here would be to attempt to match the appropriate tool or sets of } \\
\text { tools to a particular KM need or activity. }\end{array}$ \\
\hline
\end{tabular}

Table 4. Perception of the Roles and Requirements in KM.

\begin{tabular}{|l|l|}
\hline KM Issues & Perceptions, Opinions and Views from Focus Group Participants \\
\hline $\begin{array}{l}\text { The need for a } \\
\text { separate group } \\
\text { of KM practi- } \\
\text { tioners }\end{array}$ & $\begin{array}{l}\text { In order to carry out quality KM tasks, there may be a need for a separate dedicated team of } \\
\text { managers and practitioners with cross-functional business knowledge, diverse training, } \\
\text { background and specialised skills. }\end{array}$ \\
\hline $\begin{array}{l}\text { Desired attrib- } \\
\text { utes; and the } \\
\text { perceived roles } \\
\text { of a CKO }\end{array}$ & $\begin{array}{l}\text { The CKO could report directly to the CEO, and work very closely with the CIO and other } \\
\text { staff. Alternatively the CEO could undertake this role in overseeing KM initiatives. } \\
\text { Due to the emphasis and wide coverage of business and domain knowledge in KM, gener- } \\
\text { ally it may not be appropriate for the CIO or IS practitioners to lead a KM department or } \\
\text { drive KM projects. However IS practitioners should continue to work very closely with the } \\
\text { management and staff of various business domains, and to play an important role in sup- } \\
\text { porting KM efforts with the latest tools and technologies. }\end{array}$ \\
\hline
\end{tabular}




\begin{tabular}{|l|l|}
\hline $\begin{array}{l}\text { Requirements } \\
\text { of a KM prac- } \\
\text { titioner; and } \\
\text { related issues }\end{array}$ & $\begin{array}{l}\text { The prospective candidate should possess the relevant domain knowledge; be able to under- } \\
\text { stand the organisational business well; have good working knowledge and overview of in- } \\
\text { formation technologies (IT); and good team-working and communications skills. In addi- } \\
\text { tion, the candidate should have some basic understanding of the psychological and educa- } \\
\text { tional aspects related to the thinking and learning processes in people. Prior knowledge of } \\
\text { the business domain could facilitate the comprehension, content organisation and indexing } \\
\text { of the knowledge captured. }\end{array}$ \\
$\begin{array}{l}\text { However one concern here is that a KM practitioner may be too close to the business do- } \\
\text { main itself, with thinking patterns very similar to that of the domain expertpractitioner. As a } \\
\text { result this could possibly hinder the KM practitioner from perceiving issues from a fresh } \\
\text { perspective. Also, by being too close to the domain may lead to assumptions of pieces of } \\
\text { knowledge (which could be deemed common-sense or trivial by domain practitioners) } \\
\text { which may result in the omission of such knowledge and information during the knowledge } \\
\text { acquisition process. } \\
\text { Another view holds that KM practitioners may not necessarily be required to possess do- } \\
\text { main knowledge, but instead should be equipped with specialised KM expertise such as spe- } \\
\text { cial knowledge acquisition, handling or engineering skills. }\end{array}$ \\
\hline
\end{tabular}

\section{FINDINGS AND DISCUSSIONS}

The data summarised and presented in the above section serves as a basis for deeper reflection and sense-making from an interpretative and critical perspective, in the empirical context of the participants' backgrounds and work domains. In the following section, theoretical frameworks (figures 1-7) and their corresponding propositions are further induced which are grounded based on the empirical data collected from the focus groups.

\section{Analysis of Focus Group Results}

Issues surfaced from the focus group discussions generally fall into two main streams. Natural Knowledge Management (NKM) issues generally covers human-centred, non-technical, $\mathrm{KM}$ issues and solutions at the individual or organisational level. Artificial Knowledge Management (AKM) issues are usually associated with technical or technology-based KM issues and solutions.

\section{Conceptualising Knowledge and Knowledge Management}

From the data, discussion topics under this category mainly revolved around NKM issues. The literature has diverse views on the concept of knowledge and KM as these concepts are explored from different angles. For instance, according to Awad (1996), knowledge can be classified according to its nature and form, its source, the way it is used, and its purpose and relevance. Foray and Lundvall (1996) propose four different types of knowledge based on their contexts and usage: know-what; know-why; know-how; and know-who. Polanyi (1966) distinguishes between two aspects of knowledge: tacit and explicit knowledge. From a knowledge flow and conversion perspective, Nonaka and Takeuchi (1995) postulate four inter-connected, spiralling modes of knowledge conversion based on the assumption that knowledge is created through the interaction between tacit and explicit knowledge. These are socialisation (tacit knowledge sharing between individuals), externalisation (articulating tacit knowledge into explicit concepts), combination (integrating different explicit sources into new explicit knowledge base) and internalisation (embodying explicit knowledge into tacit forms through organisational practices).

Generally, focus group participants were unable to make a clear distinction between information and knowledge, in terms of form and structure. However, attempts have been made to differentiate these two concepts based on their levels of content summary, the manner in which it is internalised within a person, and the contexts of their applications. Comprehension of the concept of tacit and explicit forms of knowledge, as proposed by Polanyi (1966), was also demonstrated, although the process of the flow and inter-conversion of knowledge were not well understood. Some attempts have been made to explore the different types of knowledge such as know-what, know-how, knowwhy and know-who, as mentioned by Foray and Lundvall (1996). The participants also appeared to have a better grasp of the concept and procedures of KM than the more abstract concept of what is or is not "knowledge" and "information". This is not surprising since KM may be regarded as a process with various types of activities associated 
with it such as knowledge capture, sharing, storage, distribution, etc., which could be easily conceptualised and broken down into more tangible sub-processes and components.

\section{Existing Organisational Structures and Practices}

NKM issues were mainly discussed along this thread of topics. Currently, according to the focus group participants, most organisations have yet to formulate or adopt a formal $\mathrm{KM}$ agenda, despite the growing awareness and interest in $\mathrm{KM}$. Having a team of $\mathrm{KM}$ practitioners and the right organisational culture are considered the two most important factors that drive $\mathrm{KM}$. Existing organisational practices such as staff suggestion schemes, discussion sessions, human resource functions (rewards, appraisals, defining new $\mathrm{KM}$ roles and responsibilities) to facilitate and motivate knowledge sharing; managing business operations in line with quality management practice requirements; increased interest and support from the CEO and top management; all of which could be ideal foundations for creating a conducive KM culture and for the development of a good organisational NKM strategy. Some of these issues are commonly elaborated by authors in KM practice-oriented literature (eg. Liebowitz ed. 1999; Cortada and Woods eds 1999).

\section{Technological Issues}

AKM issues were discussed along topics associated with this discussion thread. In general, technological issues for $\mathrm{KM}$ appeared to be of lower concerns among the focus group participants, although the general consensus was that $\mathrm{KM}$ may require a mix of technologies to support $\mathrm{KM}$ activities such as the identification, acquisition, development, dissemination, use, and preservation of the enterprise's knowledge. Technologies commonly implemented in organisations were perceived to be suitable for KM. Popular tools adopted in organisations include groupwares (eg. Lotus Notes), internet/intranet/ web servers, search engines, agents, information databases and data warehouses. The focus group participants, all of which were IS professionals, appeared confident of the current state of technological capabilities available in the market for the support of KM tasks. However, noticeably, there were very little or no discussion about the significance of intelligent technologies and methodologies such as the use of artificial intelligence (AI) and expert systems for $\mathrm{KM}$, despite extensive support and claims from literature in this area advocating their links to KM (eg. Smith and Farquhar 2000; Liebowitz 2001). This category of systems have so far received marginal attention among the focus group participants as their technological capabilities were not discussed very much. Apparently these technologies have not been widely adopted in organisations, nor were they regarded as strategic KM enablers, even though they are expected to play an increasingly important role in KM. Other intelligent technologies, such as data mining, were only beginning to be explored by organisations in Singapore and were generally not very much associated with the concept of KM. Enterprise modelling technologies were also not associated with KM in any way at this stage of discussion.

\section{Desired Attributes of a KM Practitioner}

With regards to the qualifications and requirements of an ideal $\mathrm{KM}$ manager or practitioner, there seemed to be a high calling for this new breed of professionals. The desired types of background training, skills and knowledge required or expected have been discussed at length. However the focus group participants did not express clearly what exactly should be the roles and responsibilities of these KM professionals; how they can co-operate and work together with existing groups of professionals (eg. business and IS professionals), and how and where they can fit into the organisation as a whole. Discussion topics under this category mainly revolved around NKM issues, with occasional references to AKM elements as the focus group participants attempted to propose necessary skills and background training in accordance to the needs of desired KM technologies. Presently there are very little or no discussion pertaining to issues associated with relevant skills and prerequisites of KM practitioners in the IS and KM literature, although there are some literature which explore the roles and functions of KM professionals.

In summary, a growing number of these organisations appear to have existing infrastructures and management practices which we believe, would serve as a conducive foundation for implementing KM. Our study further reveals that the focus group participants are also grappling with a couple of open-ended issues which they have not quite come to terms with. These include:

- How can the structure and context of knowledge be best defined?

- How can we create a conducive, pro-KM, organisational culture and environment? 
- How can AKM methods be used effectively for tapping tacit knowledge (facilitating tacit to explicit knowledge conversion) which is also a difficult problem commonly echoed in literature (eg. Nonaka and Takeuchi 1995, p.62; Holtshouse 1998)?

- What are the strategic roles of intelligent technologies in KM in the respective domains of application?

\section{Framing KM Issues and Implications to IS}

Based on the results and $\mathrm{KM}$ issues extracted from our focus group findings, tabulated in the previous section, we proceed to induce conceptual structures which frame up various aspects of KM issues perceived by organisations. These frameworks, as illustrated in figures 1-7, put in perspective, the perceived influential dimensions, factors and contexts surrounding specific KM issues raised by the focus group participants. The frameworks highlight conceptual, organisational and technological aspects of $\mathrm{KM}$ along themes such as: characteristics of knowledge (as differentiated from information), usefulness of knowledge and $\mathrm{KM}$ value; diffusion and adoption of $\mathrm{KM}$; knowledge sharing; knowledge acquisition and capture; effectiveness of KM technologies; and requirements and qualifications of a KM practitioner. Direct inputs from the focus group discussions generated among the industry participants have facilitated the grounding of the constructs of each framework. These cognitive structures or frames, together with proposition statements, which collectively form a perception profile of CIOs and IS managers on how or what they perceive about KM in the IS practice community within the Singapore context. We wish to assert that these propositions induced from the data gathered at this stage reflect the mindsets, perceptions and attitudes of the IS professionals present at the focus groups meetings, comprising a total sample size of slightly over 20 . Our research methodology adopted is not positivist in nature, but more of soliciting a diversity of empirical data for constructing frameworks, who will in turn be used to guide theory grounding and sense-making.

Proposition 1: IS managers tend to perceive the concept of "knowledge" to be different from "information" based on attributes such as the degree of knowledge summarisation, relevance and internalisation.

Figure 1 suggests the perception that "knowledge" can be distinguished from "information" based on the degree of information summarisation, its relevance to a subject matter or task, and to the degree to which it can be internalised within a person. With respect to the outputs of IS-based KM systems, the content should be increasingly more distinct from "information" or "data" and becoming more knowledge-based, in the sense that it should be more readily comprehended and applied to various work contexts by users. In other words, the amount of physical and cognitive effort by users to pre-process the system content before it is ready to be absorbed and applied, should be reduced on the part of the human users.

Proposition 2: IS managers tend to perceive the notion that KM value depends on the perceived usefulness of knowledge and its associated attributes and factors.

Figure 2 suggests the perception that the ultimate value of a $\mathrm{KM}$ effort in an organisation will depend on the perceived usefulness of the knowledge itself which can be measured according to its perceived applicability, its perceived ability to support a task at hand (eg. in decision-making or problem resolution), and its perceived obsolescence in the context of dynamic business, organisational and technological requirements, and certain nature of business and operations and the associated types of knowledge. In the contexts of developing IS-based solutions to support $\mathrm{KM}$ or implementing related $\mathrm{KM}$ activities for the purpose of constructing effective and useful KM systems, the effectiveness of the system in facilitating the application of knowledge to a domain problem or task at hand is an important consideration.

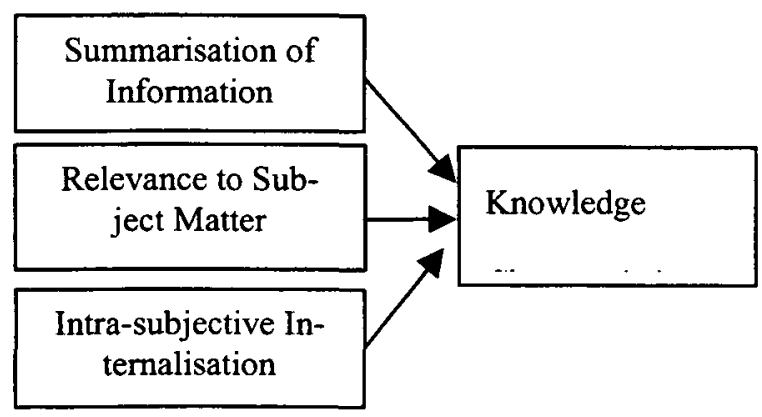

Figure 1. Characteristics of Knowledge.

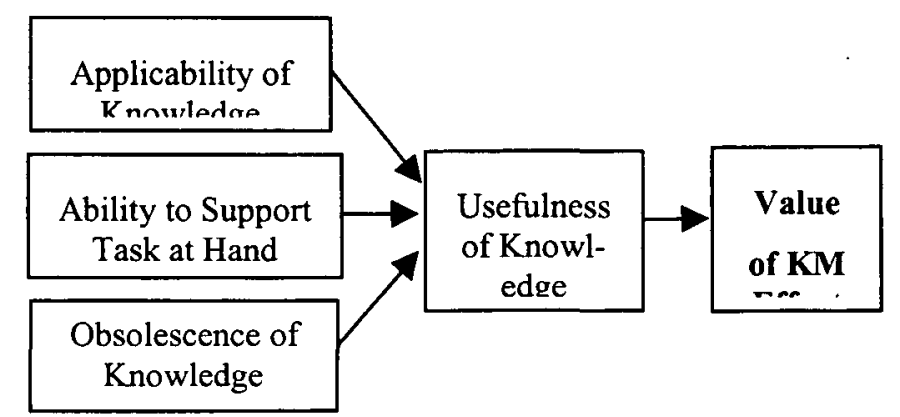

Figure 2. Usefulness of Knowledge and KM value. 
Proposition 3: IS managers tend to perceive the notion that the successful adoption and diffusion of KM depends on both internal organisational factors (availability or appropriateness of KM champion, solution provider, culture, mindset, structure, policy, resources and infrastructure) and external factors (pressures arising from economical, environmental, industry trends, etc).

Figure 3 suggests the perception that the diffusion and adoption of $\mathrm{KM}$ is dependent on various factors including the state of infrastructure and resources; the intensity of "push" by the KM champion and "pull" by solutions provider; organisational culture, structure, and mindset of workers; as well as other pre-occupations and external factors (eg. the impact and aftermath of the Asian economic crisis, the Y2K problems, ISO 9000 and other quality management certification programs). These factors could potentially facilitate or inhibit $\mathrm{KM}$ adoption by influencing managers' decisions whether to initiate or terminate potential $\mathrm{KM}$ projects, depending on how organisations react towards these factors and how they prioritise KM projects in the light these considerations. The perceived success of adopting tools and technologies associated with KM and requirements of related IS management efforts will indirectly depend on the above factors.

Proposition 4: IS managers tend to perceive the notion that the success and effectiveness of knowledge sharing in an organisation depends on factors such as the willingness of people to share knowledge, the quality of knowledge content, the effectiveness of sharing mechanisms, and the ability to resolve confidentiality and security issues.

Figure 4 highlights perceived factors which may affect knowledge sharing at both individual and organisational levels. These factors include the quality of shared or documented knowledge (which depends on the degree of biases, clarity of expression, correctness and completeness); the willingness to share (which can be influenced by the sharing culture, the passion to share, and the presence or effectiveness of motivators); effectiveness of sharing mechanisms (including organisational and technological aspects), and ability to resolve information/knowledge confidentiality and security issues. In the context of a IS-based KM system, the content quality of the system should aim to achieve those of the knowledge quality proposed in figure 4 . These tools should also incorporate suitable technologies to enable different modes of knowledge sharing among knowledge workers. KM systems should also be designed in a manner which encourages users to share knowledge through the system, with the goal of meeting the users' learning and $\mathrm{KM}$ needs as much as possible.

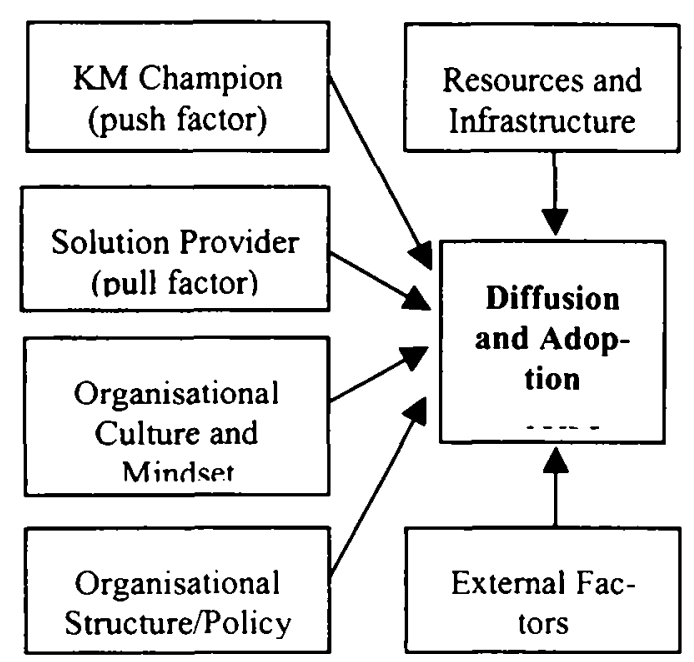

Figure 3. Diffusion and Adoption of KM.

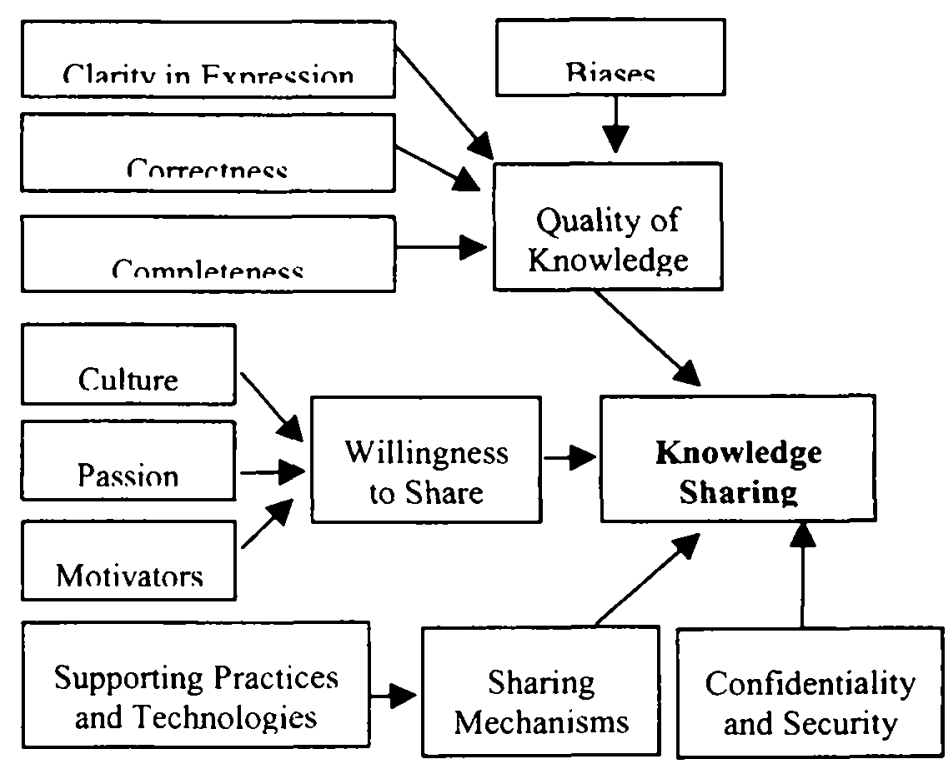

Figure 4. Knowledge Sharing.

Proposition 5: IS managers tend to perceive the notion that the effectiveness and efficiency of knowledge acquisition and capturing processes depends on factors such as motivation, rationale and applicability, the availability and suitability of existing procedures, knowledge gathering techniques required, and the scope of targeted knowledge. 
Figure 5 suggests the perception that the effectiveness and efficiency of the knowledge acquisition and capturing process is dependent on factors such as the objectives and motivations for knowledge capturing; the scope of the targeted knowledge; the availability and sophistication of the technique(s) required; and associated rationale and application context. From the systems perspective, conventional systems depend on data and information as raw inputs. As these systems become increasingly more knowledge-focussed, intelligent technologies will come into play. Specialised knowledge engineering techniques, which are traditionally used in the development of expert and AI systems may become more significant in constructing $\mathrm{KM}$ systems.

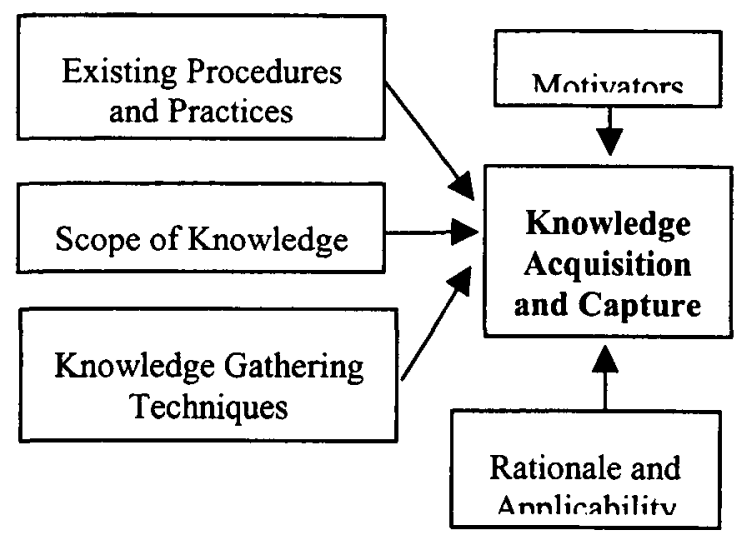

Figure 5. Knowledge Acquisition and Capture.

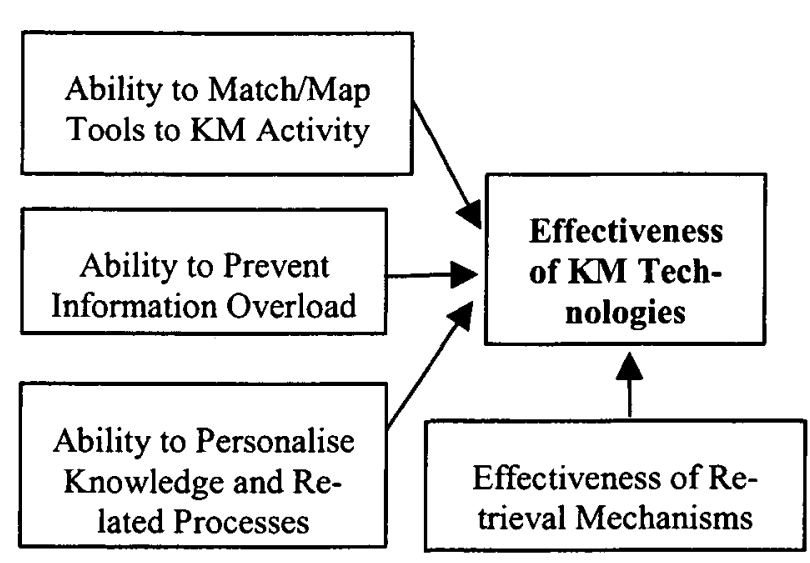

Figure 6. Effectiveness of KM Technologies.

Proposition 6: IS managers tend to perceive the notion that the effectiveness of KM technologies depends on factors such as retrieval mechanisms, prevention of information overload, ability to personalise knowledge and related processes, and the suitable matching of $K M$ tools with $K M$ activities and requirements.

Figure 6 suggests the perception that the perceived effectiveness of $\mathrm{KM}$ technologies is dependent on factors such as the effectiveness of knowledge retrieval mechanisms; the ability to prevent information overload; ability to personalise knowledge and related processes; and also more importantly the organisation's ability to match/map suitable KM tools to support appropriate KM activities, needs and requirements. Developers of KM systems would be wise to consider and incorporate some of these requirements into their systems design and development. There are also strong indications that these suggested systems capabilities and features are not commonly found in traditional IS analysis tools, and that these suggestions may be effectively realised and enabled, with the increasing use of more human-like systems approach such as specialised intelligent or AI-based technologies.

Proposition 7: IS managers tend to perceive the notion that an effective KM practitioner should ideally possess the appropriate background knowledge, basic skill sets, familiarity with the domain, and some basic understanding of psychology and learning in people.

Figure 7 suggests the perception that in selecting an ideal $\mathrm{KM}$ practitioner, some major considerations should be taken into account including his background knowledge (in areas of the business domains, IT, and cross-functional training); his basic skill sets (such as general communications, team-working, and specialised KM skills); his degree of familiarity and biases with respect to the business domain selected for KM; and whether he has some basic understanding of the psychological and educational aspects relating to the cognitive processes in people such as learning and thinking. Practitioners who are involved in the adoption, design and implementation of computer systems for the purpose of KM should be aware of the diversity of skill sets and backgrounds desired as these know-how and expertise will largely influence the design and deployment of these systems in suitable work domains and contexts, and how effectively these IS practitioners work with other non-technical KM team members and users. For instance, a domain KM problem may require a system capability to analyse loads of raw data and information. This may require the application of data mining technologies for KM. In this case, systems developers involved should possess relevant background and training in data mining or related disciplines. At the same time, they should also have acquired sufficient domain knowledge in order to appreciate the nature and needs of the problem as they attempt to formulate and design an optimal $\mathrm{KM}$ solution. 


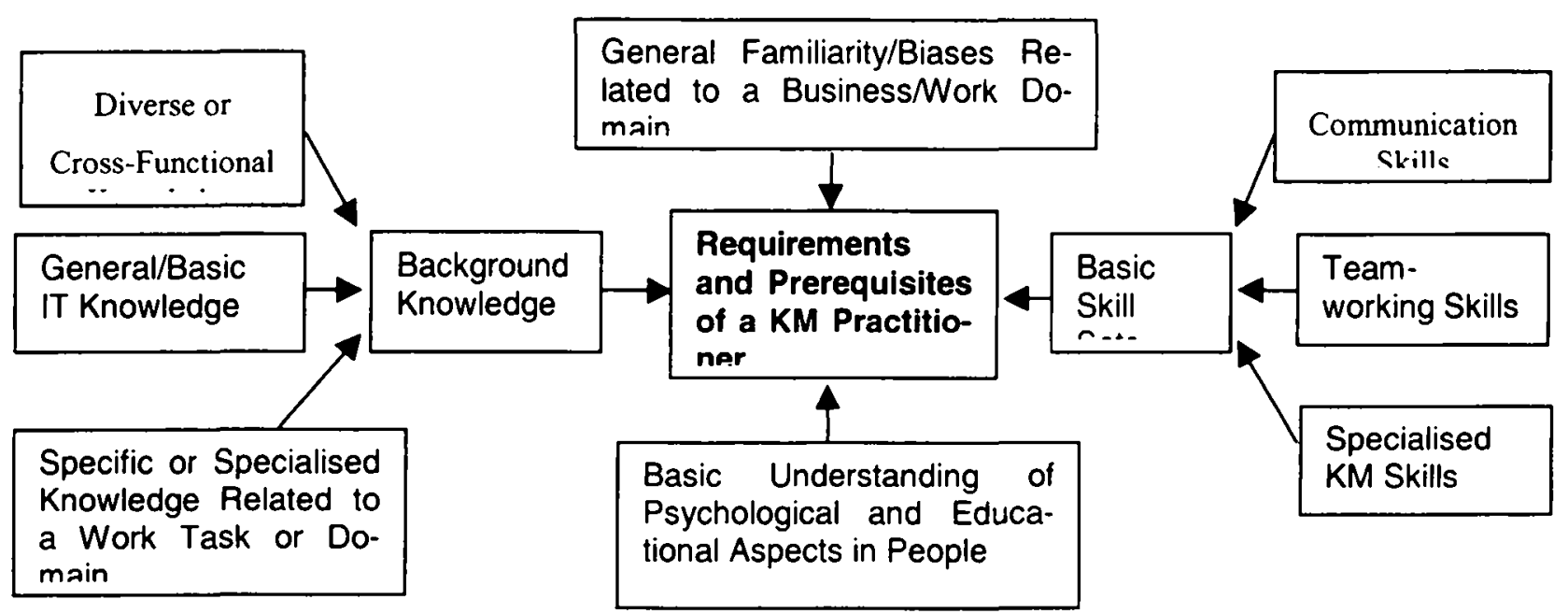

Figure 7. Requirements and Prerequisites of a KM Practitioner.

\section{KM Perception Gaps and Challenges}

In our analysis of the focus groups results, some of the issues and factors highlighted in the previous sections have important implications to the research and practice of KM and IS. Among these issues, two predominant KM challenges have emerged. First of all, the need to establish the right organisational culture, mindset, structures (practices, policies and mechanisms) is one of the most important issues facing practitioners. Managers and developers of IS or $\mathrm{KM}$ solutions need to bear this in mind as they strive to construct, use and manage such systems effectively, with the hope of generating positive side effects among users in supporting knowledge-intensive work. Secondly, the desire to tap, retain and share tacit forms of knowledge for organisational benefits remains an elusive and difficult task, with no clear solutions.

Interestingly, from our observations during the focus group sessions, there were little discussions about the adoption and application of intelligent knowledge-based systems such as $\mathrm{AI}$ techniques, and expert systems. Most technological related issues centred around more conventional technologies and platforms such as internet/intranet/web-based technologies, e-mails, group support systems, etc. On the other hand, researchers working on intelligent systems and knowledge engineering techniques which explicitly deal with knowledge, have hailed these technologies as future strategies for IS and KM (examples: AAAI 1997; Beckman 1997; Borghoff and Pareschi, 1998; Dhar and Stein 1997; Neches et al 1991; Wielinga et al 1997; Wiig et al 1997; Smith and Farquhar 2000; Tsui, et al. 2000; Liebowitz 2001). This reveals a interesting gap between practitioners' and researchers' perceptions of the potential strategic roles of intelligent knowledge-based systems in facilitating or enabling $\mathrm{KM}$ implementation. The following research questions are induced, as we try to probe further for reasons to help explain the differences in perceptions between the IS practitioners (in Singapore) and researchers, with the hope to expound on the burning issue of why IS practitioners have not adopted intelligent systems as readily as they could have during the acquisition, development and management of IS for KM.

- Were IS managers ignorant of the state-of-art research and technologies in intelligent systems, and their potential capabilities in augmenting KM activities and decision support (eg. extracting, transforming and sharing of tacit knowledge)? Similarly, were they contented with conventional information systems features to support KM?

- Was there an acute shortage of specialised skills and expertise associated with the construction of intelligent systems among IS practitioners?

- Was there resistance from IS managers towards the adoption and use of intelligent systems, either due to past experiences of failures and undelivered promises, or due to some perceived negative impacts on the knowledge content of certain tasks and job quality (Hendriks 1999)?

- Was it that the IS managers did not regard the use of intelligent systems as a strategic enabler for KM or they considered that there would be no significant benefits in using these systems?

- A combination of the above reasons? 


\section{CONCLUSION AND FUTURE DIRECTIONS}

This study has illustrated the effectiveness of focus group research as a qualitative method for an exploratory, inductive study which allows a researcher to seek a clearer understanding of industry practitioners' perceptions, attitudes, behavioural and usage patterns with respect to a new emerging technology or paradigm such as KM. Focus group was used as a mechanism for sense-making and for grounding concepts from qualitative data. These concepts were represented using frames of reference. In our study, we have extracted and categorised KM issues from the opinions and perceptions contributed by the focus group participants, from which a set of theoretical frameworks was grounded. The implications of the findings to IS-based KM have also been discussed. The results of this research effort reveal a general healthy state of KM awareness and attitudes among CIOs and senior IS professionals from several large organisations in Singapore. The findings have overridden a previous presumption that $\mathrm{KM}$ could be quite "unheard of" among industries and organisations in Singapore. At least this does not appear to be valid anymore within the IS community. As the participants were mainly CIOs and senior IS executives, the preliminary findings here may not necessarily apply to more junior IS practitioners or other non-IS executives since similar studies have yet to be conducted in Singapore. Presently some of the preliminary efforts for KM in organisations are positive steps towards the institutionalisation of KM. However these are merely exploratory and incremental in nature, often not co-ordinated by any KM plans and strategies. Our research also surfaces some difficult KM problems and challenges (such as establishing the right organisational culture/mindset, and the task of tapping tacit knowledge), while at the same time reveals the existence of a perception gap between IS practitioners and researchers (that is the perception of whether or not intelligent knowledge-based systems have potential strategic roles in IS-based support for KM).

In general, based on the results gathered from the focus group participants, one or more of the following aspects of $\mathrm{KM}$ are found to be lacking in some of these organisations. These include:

- An in-depth insight into the parts of an organisation's business and process where knowledge bottlenecks could exist or which could be relatively more knowledge-intensive in nature than other parts.

- An in-depth understanding of the magnitude and complexity of the KM problem, involving a combination of both NKM and AKM critical success factors.

- A more focussed or integrated strategic $\mathrm{KM}$ vision and plan; or incorporating $\mathrm{KM}$ as part of their corporate strategic planning.

- An appreciation of more sophisticated, intelligent or knowledge-based technologies and their relevance for IS support in the context of KM. This is understandable since KM very often requires a multidisciplinary or cross-domain platform.

- An understanding of the roles and responsibilities of $\mathrm{KM}$ professionals and how they fit into the overall picture of the organisation.

- An appropriate management approach to co-ordinate KM processes and tasks; to merge or embed KM activities into existing organisational practices and routines; as well as more specialised skill sets and tools necessary for engineering the knowledge content itself.

We hope to extend our research exploration along some of the findings and research questions induced in the previous sections of this paper, with the hope that IS researchers and practitioners could align IS initiatives, planning, and management strategies, more accurately with those of KM and business requirements.

The outcome from such studies will enable organisations to reflect deeper on their existing practices in order to decide what type of KM goals they should be setting for themselves realistically, and what level and complexity of KM effort they would really need to invest in achieving these goals. Such initiatives will facilitate their transformation into knowledge-efficient organisations as they compete in a dynamic knowledge-based economy.

\section{REFERENCES}

AAAI (1997) Artificial Intelligence in Knowledge Management, Proceedings of 1997 AAAI Spring Symposium, Technical Report: SS-97-01, AAAI Press, Menlo Park, CA.

Awad, E.M. (1996) Building Expert Systems: Principles, Procedures and Applications, West Publishing Company, St. Paul, Minn.

Beckman, T. (1997) "A Methodology for Knowledge Management," in Proceedings of the IASTED International Conference on Artificial Intelligence and Soft Computing, (ASC '97), M.H. Hamza (ed), Banff, Canada, IASTED ACTA Press, pp. 29-32.

Borghoff, U.M., and Pareschi, R. (eds). (1998) Information Technology for Knowledge Management, SpringerVerlag, New York. 
Cortada, J.W., and Woods, J.A. (eds). (1999) The Knowledge Management Yearbook (1999-2000), ButterworthHeinemann, MA, Boston, 1999.

Dhar, V., and Stein, R. (1997) Intelligent Decision Support Methods - The Science of Knowledge Work, Prentice-Hall, NJ.

Greenbaum, T.L. (1998) The Handbook for Focus Group Research, 2nd ed, Sage Publications, Thousand Oaks, CA, pp. 247.

Foray, D., and Lundvall, B.A. (1996) "The Knowledge-Based Economy: From the Economics of Knowledge to the Leaming Economy," in OECD Documents: Employment and Growth in the Knowledge-based Economy, OECD, Paris, pp. 11-32.

HBR (1998) Harvard Business Review on Knowledge Management, Harvard Business School Press, Boston, MA.

Hendriks, P.H.J. (1999) “Do Smarter Systems Make for Smarter Organisations?” Decision Support Systems, vol.27, pp. 197-211

Holtshouse, D. (1998) “Knowledge Research Issues,” California Management Review, (40:3), pp. $277-280$.

Liebowitz, J. (ed). (1999) Knowledge Management Handbook, CRC Press LLC, Boca Raton, FL.

Liebowitz, J. (2001) Knowledge Management: Learning from Knowledge Engineering, CRC Press, Boca Raton, FL, pp. 49-56.

Neches, R., Fikes, R., Finin, T., Gruber, T., Patil, R., Senator, T., and Swartout, W.R. (1991) “Enabling Technology for Knowledge Sharing," AI Magazine, (12:3), pp. 36-56.

Nonaka, I., and Takeuchi, H. (1995) The Knowledge Creating Company: How Japanese Companies Create the Dynamics of Innovation, Oxford University Press, New York.

OECD (1996) Documents on Employment and Growth in the Knowledge-based Economy, OECD, Paris.

Polanyi, M. (1966) The Tacit Dimension, Routledge \& Kegan Paul, London.

Shariq, S.Z. (1998) "Guest Editorial: Sense Making and Knowledge Management: An Assessment of Technologies and Applications from Users' Perspectives," Journal of Knowledge Management, (2:2), pp. 7-9.

Strauss, A., and Corbin, J. (1998) Basics of Qualitative Research: Techniques and Procedures for Developing Grounded Theory, 2nd ed, Sage Publications, Thousand Oaks, CA, pp. 3-14.

Smith, R.G., and Farquhar, A. (2000) "The Road Ahead for Knowledge Management: An AI Perspective," AI Magazine, (21:4), Winter 2000, pp. 17-40.

Tsui, E., Garner, B., and Staab, S. (eds). (2000) Knowledge-Based Systems: Special Issue on Knowledge Management, (13:5).

Weick, K. E. (1995) Sensemaking in Organizations, SAGE Publicaitons, Thousand Oaks, CA.

Wielinga, B., Sandberg, J., and Schreiber, G. (1997) "Methods and Techniques for Knowledge Management: What Has Knowledge Engineering To Offer?” Expert Systems with Applications, (13:1), pp. 73-84.

Wiig, K.M. (1997) "Knowledge Management: An Introduction and Perspective," Journal of Knowledge Management, (1:1), pp. 6-14.

Wiig, K.M., Hoog, R., and Spek, R. (1997) "Supporting Knowledge Management: A Selection of Methods and Techniques," Expert Systems with Applications, (13:1), pp. 15-27. 